\title{
Numerical Modelling of The Behavior of Tunnel in Soft Surrounding Rock. A Case Study of Djebel El- Ouahch Tunnel, Algeria.
}

\section{Barkane Aicha}

University of Constantine: Universite Constantine 1

Sami Mezhoud ( $\square$ mezhoud_sami@yahoo.fr)

University of Constantine 1: Universite Constantine 1 https://orcid.org/0000-0003-4751-1556

\section{Original Paper}

Keywords: tunnel, soft rock, stresses, strains, stability, Plaxis 3D

Posted Date: February 4th, 2021

DOI: https://doi.org/10.21203/rs.3.rs-163604/v1

License: (c) (1) This work is licensed under a Creative Commons Attribution 4.0 International License. Read Full License

Version of Record: A version of this preprint was published at Geotechnical and Geological Engineering on May 6th, 2021. See the published version at https://doi.org/10.1007/s10706-021-01841-9. 

A Case study of Djebel El-Ouahch tunnel, Algeria.

\author{
Barkane Aicha1, Samy Mezhoud².
}

\title{
4 Abstract
}

The response of a massif to stresses generated by tunnel excavation depends essentially on the geological conditions, the geometry of the tunnel and its underground position. The major

7 problem related to the construction of these structures is to ensure the stability of the whole tunnel-ground, by controlling the various deformation generated during the construction

9 In this context, the present paper examines the effect of these conditions on the behavior of

10 tunnels and the surrounding soil. The study is applied to a real tunnel, in this case the tunnel of

11 Djebel El Ouahch, Algeria was taken as a reference model. The research includes a parametric study to evaluate the effect of several parameters on the behavior of the tunnel and surrounding

13 soil such as the tunnel anchoring depth, the tunnel-soil interface rate, and the shape of the tunnel 14 cross section. The analysis is performed using the PLAXIS 3D TUNNEL calculation code with an elastoplastic Mohr-coulomb model for the soil behavior. The results show that the strongest

16 and most stable position is the mid-deep tunnel with a circular section, with a non-slip interface 17 between the tunnel and the ground. These outcomes can help to understand the effects of various influences parameters which control the stability of the tunnel in a soil with bad characteristics.

19 Keywords: tunnel, soft rock, stresses, strains, stability, Plaxis 3D.

\footnotetext{
${ }^{1}$ Dept. of Civil Engineering, University of Mentouri Constantine, Algeria.

${ }^{2}$ Laboratoire de la Mécanique des Sols et des Structures (LMSS), Algeria.
} 


\section{Introduction}

21 Underground structures in urban areas have specific characteristics linked to their function and nature of the environments crossed. They are in fact located at shallow depth in saturated zones with multiple underground infrastructures, or located at great depth depending on their functions (Bousbia 2016). The construction of this kind of structure often encounters stability problems generally due to poor geological, geotechnical or hydrological conditions. For this reason, their design is now based on in-depth geotechnical studies and risk analyzes in order to ensure the safety of the structures and their users (Idris 2007). In addition, the construction of underground structures, especially the case of urban tunnels, creates risks specific to all stages of the project and in particular during its construction stage. These risks have several origins (Grasso et al. 2004) : 1) Geotechnical and geological risks that are linked to insufficient information obtained during the reconnaissance campaign, or the ability to predict the soil's response to the digging action; 2) The risks study related to the difficulty of the project in adapting to the actual conditions; 3) Risks of excavation process related to the choice of an inappropriate or poorly controlled construction method during instability phenomena; and 4) the experience of the construction team and contractual constraints.

Furthermore, according to Oggeri and Ova (2004) typical risks related to instabilities in underground structures are:1) Strong deformations associated with the reduction of the cross section which compromises the use of the structure in optimal safety conditions. This deformation can result from several factors such as swelling, creep, plastic deformations, tectonic stresses. The consequences of the convergence are the closing of the section, the destruction of the support. Sometimes this phenomenon requires the re-excavation of the underground structure. In this context, the Tymfristos road tunnel in Greece is a good example. 2) Surface settlement or differential settlement, in which the digging in soft ground often 
generates a settlement of the soil above the tunnel, which can damage the infrastructure located on the surface.

Additionally, in the case of road excavations, the swelling of the ground by decompression can cause serious problems such as the reflective cracking, during construction and after the commissioning of the structure (Mezhoud et al. 2017a, 2018b). This situation is also observed during the digging of old tunnels in swelling ground, in which, it is not uncommon to observe a raft heave reaching several tens of centimeters. The repair of the linings and the re-excavation of the raft thus become a regular maintenance operation. In other cases, it becomes mandatory to construct inverted vault rafts, intended to limit movements to an acceptable value (Berkane and Karech 2018; Bultel 2001).

Another key factor, the design study of a tunnel according to Benamar (1996), is mainly used to determine the convergences and stress states around the tunnel in order to analyze the state of equilibrium at long term. Obviously, other parameters may attract the attention of the designer, such as induced settlements on the surface, damage to other surrounding structures, the stability of the working face during excavation, etc. In addition, there are numerous factors that have been identified by several authors, and can influence seriously the tunnel equilibrium:1) excavation method; 2) installation time of the support and its nature; 3) nonlinearity of the behavior of the soil; 4) initial stress field; and 5) geometric shape of the tunnel section. This last condition can strongly influence the forces and bending moments supported by the support. 
Indeed, in the literature, several authors correlate the vulnerability of a tunnel to certain relevant factors such as: the tunnel cover (depth), the type of soil, the conditions of the soil-tunnel interface, the thickness of the lining, and the shape of the tunnel. Khoshnoudian (1999), studied the influence of the tunnel depth on the internal forces (bending moments and shear effort) induced in the tunnel lining, three configurations $\mathrm{H} / \mathrm{D}=(1.2,1.8$ and 2.4) which correspond respectively to a tunnel close to the ground surface was examined. He noticed an increase in these efforts with depth. These results are in agreement with those presented by Owen and Scholl (1981). Sliteen (2013), examined the effect of the tunnel depth. The numerical simulations carried out for two values of the tunnel depth $H=1.8 \mathrm{D}$ and $\mathrm{H}=3 \mathrm{D}$ (D; tunnel diameter) corresponding respectively to a shallow tunnel and to a deep tunnel. The results obtained confirm that the depth effect is important for the normal effort; this influence is less significant for the bending moment and the shear effort. Patil et al. (2018), studied the influence of tunnel anchoring rate (depth), soil-tunnel interface conditions, tunnel shape, on the behavior of the shallow tunnel in soft soil, it has been observed that the distortion in the tunnel lining depends on the anchoring depth. It can be seen that the ovaling (in a circular tunnel) and the racking (in a rectangular tunnel) decrease considerably when the anchoring rate is greater than 2. Almost 6 to $18 \%$ greater distortion and $20 \%$ moment of higher bending are obtained in total slip interface condition compared to the non-slip interface condition. An unconventional square tunnel with rounded corners, produces a bending moment $55 \%$ lower than that of the square tunnel. Berkane (2020), studied the influence of the tunnel anchoring rate (depth), on the behavior of the shallow tunnel in a soft rock (argillite), it was observed that the decrease in depth of the tunnel increases the risk of instability of the ground-tunnel system, and increasing this depth contributes to its stability. 
Despite the fact that several authors have studied several factors, but studies regarding the behavior of the tunnel during the digging in a soft rock are almost overlooked. For this reason, the main purpose of this work is the prediction and the understanding of this behavior during digging operation in a ground with bad characteristics (soft rocks), in order to limit the various deformations during tunnel construction, and consequently to ensure good resistance and stability of the tunnel. For this reason, the current work consists of establishing a threedimensional digital model using the Plaxis 3D tunnel calculation code of part of the "Djebel El Ouach"tunnel. This model is used to perform a parametric study in order to assess the effect of the tunnel depth and the shape of the cross section of the tunnel, as well as the effect of soiltunnel interface rate on the behavior of the tunnel, and its surrounding soil.

\section{Numerical modeling of the case study}

The "Djebel El Ouahch" tunnel in Constantine province (Algeria) was chosen as case study. This tunnel is part of the construction of the Maghreb Unity Motorway (AUM), approximately $7000 \mathrm{~km}$ in length, crossing Algeria with a length of $1200 \mathrm{~km}$. The tunnel belongs to section 4.1 of this highway. It crosses Djebel El-Ouahch mountain in the northeast of the province of Constantine and includes two practically parallel tubes with a total length of 1909m (Figure 1a). The tubes are separated by a distance of $24 \mathrm{~m}$. The maximum tunnel coverage is around $119 \mathrm{~m}$, and the most critical section corresponding to the weakest coverage is $12 \mathrm{~m}$. Figure (1b) illustrates a plan layout of the tunnel T1, and Figure (2) presents the transverse dimensions of the tunnel.

According to the geological and geotechnical investigation of the project, the tunnel passes through argillite soil. The mechanical characteristics of soil in the comprising section are 
113 summarized in table (1) and presented in Figure 3. The ground is modeled as a perfectly plastic-

114 elastic material with a fracture criterion of Mohr-Coulomb.

115 In the case of Djebel El-Ouahch tunnel, indirect conservation interventions such as Fiber glass 116 tubes (FGT) were used to improve the soil condition. Globally, the reinforcement consists of 117 HEB 200 metal hangers, $40 \mathrm{~cm}$ layer of shotcrete, welded wire mesh, anchor bolts and fiberglass 118 tubes to the advancement core. The temporary support of the tunnel is modeled by quadrilateral 119 plate (flat) elements at 8 nodes. Plates are structural elements used to model slender structures 120 placed in the ground and having significant flexural stiffness "EI" and normal stiffness "EA". 121 Since there are two elements (shotcrete and hangers), it is appropriate to use equivalent bending 122 and normal stiffness for both elements (shotcrete and hangers). Table 2 summarizes the 123 mechanical characteristics of the shotcrete and hangers. The calculation of the equivalent 124 stiffnesses: bending and normal of the shotcrete and bends is managed by the following 125 equations:

$$
\begin{gathered}
E I e q=E b \cdot I b+\left(\frac{E \operatorname{cin}}{E b}-1\right) \frac{E b \cdot I c i n}{d} \\
E A e q=E b \cdot A b+\left(\frac{E \operatorname{cin}}{E b}-1\right) \frac{E b \cdot A c i n}{d}
\end{gathered}
$$

128 The used bolts are distributed seal bolts type (with cement mortar sealing), spaced 1m apart 129 along the tunnel axis. The bolts are modeled by linear elements (geogrids) and the bolt-ground 130 connection is assumed to be perfect. Table .3 summarizes the mechanical characteristics of 131 bolts.

132 The reinforcement method of the tunnel includes the use of polymer inclusions reinforced 133 with very long glass fibers GFRP (Glass fiber reinforced polymer) sealed in the ground by an 134 injection system using a cement grout in order to stabilize the working face, and to oppose the 
135 deformations and stresses generated by the movement of the ground in different directions.

136 Table .4 summarizes the mechanical characteristics of "GRFP" tubes. In addition, the distance

137 between the bars is $1.5 \mathrm{~m}$ vertically, $2.5 \mathrm{~m}$ horizontally, and the length of the tube is $19.5 \mathrm{~m}$.

138 (Berkane and Karech 2018).

139 For the numerical modeling of the reinforcement of the face, it is necessary to apply to each

140 phase a force determined directly by the formula given by the simplified approach of Peila

141 (1994) which consists of taking into account the longitudinal reinforcement of the front by a

142 pressure exerted at the waistline. This pressure is the sum of the forces in the bolts brought back

143 to the surface of the front and is equal to:

$$
\text { Pfront }=\min \left\{\frac{n \cdot A \cdot \sigma a d m}{S}, \frac{n \cdot S A \cdot \tau a d m}{S}\right\}
$$

145 With: $n$ : number of bolts $(\mathrm{n}=55 \mathrm{bolt}) ; A$ : cross section of a bolt; $\sigma$ adm: Maximum admissible

146 stress in tension in a bolt; $S$ : excavated surface; $S A$ : the total lateral anchoring surface; and

$147 \tau$ adm: Maximum admissible shear stress at the bolt - ground interface.

148 Table 4. Mechanical characteristics of "GRFP" tubes Glass fiber reinforced polymer.

149 The final coating is made of $40 \mathrm{~cm}$ of B25 concrete. The characteristics retained for the

150 calculations are: Volume weight $\sigma \mathrm{b}=25 \mathrm{kN} / \mathrm{m}^{3}$, Surface $=0.4 \mathrm{~m}^{2}$, Density $=2500 \mathrm{~kg} / \mathrm{m}^{3}$, 151 instantaneous modulus of deformation $\mathrm{Eb}=30.000 .0000 \mathrm{KN} / \mathrm{m}^{2}$, and Poisson's ratio is $v \mathrm{~b}=$ 1520.2.

153 The numerical modeling consists of creating a simplified representation of tunnel digging and 154 construction process, using the PLAXIS3D TUNNEL software, to deduce the various stresses 155 due to the soil-support interaction on the overall tunnel behavior. triangular elements with 15 
156 nodes are adopted, the pressure coefficient of the earth at rest " $\mathrm{K}_{0}$ "is taken equal to 1 , with the 157 use of a deconfinement rate $(\lambda)$.

158 With : $\sigma \mathrm{r}=(1-\lambda) . \sigma 0 \quad(\sigma o:$ is the initial stress and $\sigma r:$ is the fictive pressure $)$.

159 The boundary conditions retained are as follows: 1) zero horizontal displacement on the lateral

160 limits; and 2) zero vertical displacement on the lower limit. It is assumed also that the water

161 table is below the tunnels.

162 The calculations were carried out considering the following phasing:

163 - Phase 0: initialization of constraints (geostatic constraints)

164 - Phase 1: total digging of the left tunnel and temporary retaining structure over a length of $6 \mathrm{~m}$ $165(\lambda=1)$. Flat front, SLICE 1.

166 - Phase 2: excavation of 2-m cap; SLICE2, SLICE3, SLICE4 with deconfinement $(\lambda=0.4)$.

167 - Phase 3: temporary support installation hanger + shotcrete + anchor bolt (for the excavation 168 part-calotte); Plane A slice 2, Plane B slice 3, Plane C slice 4; with deconfinement $(\lambda=1)$.

169 - Phase 4: excavation of 6-m Stross; SLICE2, SLICE3, with deconfinement $(\lambda=0.4)$.

170 - Phase 5: installation of temporary support hanger + shotcrete + anchor bolt + reinforcement of 171 face by the application of the force of pressure; Plane A slice 2, Plane B slice 3; deconfinement $172(\lambda=1)$.

173 - Phase 6: excavation of the raft at $6 \mathrm{~m}$; SLICE2, with a deconfinement $(\lambda=0.25)$.

174 - Phase 7: support to strike off; Plane A slice2, $(\lambda=1)$.

175 - Phase 8 to phase 14: repeated the same phases from 1 to 8 for the right tunnel. 
176 The following Figure 4 presents the three-dimensional model of the case studied in a Cartesian

177 coordinate system $(\mathrm{o}, \mathrm{x}, \mathrm{y}, \mathrm{z})$.

178

179 Results and discussion

Effect of the Tunnel depth $(\mathrm{H})$

181 The influence of the tunnel depth $(\mathrm{H})$ on soil behavior is considered through three values located

182 above the keystone of the tunnel. Additionally, to the real depth of the tunnel at this location $(\mathrm{H}$

$183=110 \mathrm{~m}$ ), two other tunnel depths are considered, $\mathrm{H}=50 \mathrm{~m}$ (mid-deep tunnel), and $\mathrm{H}=20 \mathrm{~m}$

184 (case of shallow tunnel). The results obtained are compared in order to detect the most stable

185 tunnels location. The results are presented in Figure 5 in term of stress and deformation 186 condition of the left tube.

187 The results indicate that the stresses induced to the soil around the wall of the tunnel cavity

188 (Figure 5.a) are directly proportional with the tunnel depth which translates into the stability of

189 the stress values for all the three cases. The strong and the shallow depth of the tunnel generates

190 significant deformations in the soil around the wall of the left tunnel cavity (Figure 5.b), on the

191 other hand an average tunnel depth greatly reduces these deformations. The accentuated

192 deformations were due to several factors such as: convergence due to high tunnel depth, the

193 case of the deep tunnel, and low compressive strength of argillite in the case of shallow tunnel

194 (AFTES 2003a, 2003b). These deformations can cause cracks in the soil mass. These results

195 are in conformity with those of Patil et al. 2018, which indicated that the tunnel lining tends to

196 distort more at a shallow depth. Distortion in the tunnels that are buried at a deeper depth shows

197 less ovaling in case of a circular tunnel and racking in case of a rectangular tunnel. 
In other hand, as presented in Figure 6a, the stresses induced in the wall support of the left tube are proportional to the depth of the tunnel. However, these stresses in all cases are gradually reduced until they are canceled. These results are in accordance with the "Convergence-confinement" method (Panet and Guellec 1974; Panet 1995). The convergence is linked to soil conditions and explained by the phenomenon of soil swelling.

In the case of deformations (Figure 6b) at the level of the wall of the left tube, they are almost nil for the cases of $50 \mathrm{~m}$ and $20 \mathrm{~m}$ depth (medium, and shallow depth), whereas these deformations increase rapidly in the case of the reference model (high tunnel depth). This situation can be explained by the effect of the strong convergence of the ground in the case of 207 the deep tunnel.

Figure 7 a presents the settlement at the free surface of the soil for three different depths of the tunnel. The settlement is very variable and directly proportional to the depth of the tunnel. In addition, it is observed a very important uplift in the ground under the base of the left tube 211 of the tunnel for all three cases (Figure 7b). This ground uplift is due to the swelling of the argillite and it increases with increasing the tunnel depth.

\section{Effect of the shape of the tunnel cross section}

214 According to the literature (Benamar 1996; Patil et al. 2018), the shape of the tunnel has a

215 significant impact in terms of stress and strain induced to the soil, or flexing moments induced 216 to the tunnel support. The results presented by Patil et al. (2018) show that the maximum 217 amount of thrust is generated in the tunnel lining that is square with rounded corners because 218 of the combined action of the hoop and normal thrusts, this kind of combined action of thrusts 219 is different in case of other shapes of tunneling. In addition, the circular tunnel performs better 220 than other tunnel shapes in terms of development of stress. 
221 For this reason, the performance of various conventional shapes of tunneling, such as circular,

222 square and elliptical (the reference model), have been analyzed (Figure 8a and 8b).

223 In addition, the stresses induced in the soil around the wall of the cavity of the left tube of the 224 tunnel increase rapidly in the case of the square section then decrease until they cancel each 225 other out. On the other hand, in the two other sections (reference and circular), the stresses 226 become very high and remain stable. Note that both models (circular and elliptical) generate 227 large deformations that occur in the ground around the left tunnel, especially in the case of the 228 circular model, however, the square model significantly reduces these deformations.

It can be seen also, that the variation in shape of the cross section of the tunnel has no effect on the stresses induced in the support of the left tunnel cavity (Figure 9a and 9b). In addition, 231 it is observed that the circular shape of the tunnel greatly reduces the induced deformations at 232 the level of the wall of the left tunnel tube while they are very important in the case of the 233 elliptical section (reference model) and null in the case of the square section.

234 Moreover, the circular shape of the tunnel section generates very low settlement value (Figure 235 10a), comparing with the other two forms of section. It is observed a very significant uplift of 236 the ground under the base of the left tunnel tube in the case of the reference model (Figure 10b), 237 less important in the case of the circular section and moderate in the case of the square section 238 of the tunnel. i.e., the circular tunnel performs better than other forms of tunnel in terms of 239 surface settlement and displacement under the raft of the tunnel.

\section{Effect of interfaces}

241 The soil structure interaction effects are closely related to the interface characteristics between

242 the structure and the surrounding soil. They are expected to be increased in cases of non-circular 243 (i.e., rectangular) embedded structures (Tsinidis et al. 2013). According to M. Patil and al. 
244 (2018), the soil-tunnel interface conditions also contribute to the reduction of the distortion in 245 the tunnel lining, in which the distortion in the full-slip interface condition is found to be 6$24618 \%$ more than that in the no-slip interface condition. For this purpose, three interface stiffness 247 coefficients were taken in consideration: 1 ) the case of full slip: $R_{\text {inter }}=0.1$; the case of medium 248 slip: $R_{\text {inter }}=0.5$ which is the reference model; and 3$)$ the case of full slip: $R_{\text {inter }}=1$. The results 249 are shown in Figure 11a and Figure11b in term of state of stress and deformation induced in the 250 soil around the tunnel wall, Figure 12a and Figure $12 \mathrm{~b}$ in term of state of stress and deformation 251 induced to the tunnel wall, and Figure 13a and Figure 13b in term of settlement and vertical 252 displacement.

253 The results show that the stresses induced in the soil around the wall of the left tunnel tube 254 (Figure 11a) are very different in the 3 interface cases for $\mathrm{R}=0.1$ the stresses increase rapidly 255 up to the value of $3300 \mathrm{kN} / \mathrm{m} 2$ and then stabilize. In the case of $\mathrm{R}=0.5$ the stresses grow 256 slowly and stabilize at a value less important than that in the case of interface $\mathrm{R}=1$ which 257 generates high constraints. In term of deformations induced in the soil around the wall of the 258 left tube of the tunnel (Figure 11b), the values decrease and then stabilize in all three interface 259 cases. The low value of the interface ratio causes very high strains; on the other hand, increasing 260 this ratio decreases the strains in a remarkable way.

261 In the case of the stresses induced in the tunnel wall (Figure 12a), they are for all three 262 interface cases very large at the beginning and then gradually decrease until they cancel each 263 other. This mean that there is no effect of varying the interface rate on these constraints. In term 264 of deformations induced at the level of the tunnel wall (Figure 12b) they increase rapidly in the cases of $\mathrm{R}=1$ and $\mathrm{R}=0.1$, but in the case of $\mathrm{R}=0.5$, the deformations continue their progression 266 with a change of their signs. It can be seen that the deformation increases significantly if the 
slip between the ground and the tunnel is total or zero, and considerably when the slip between the ground and the tunnel is partial.

The curves of the settlement at the surface of the ground above the left tunnel (Figure 13a) are almost identical and confused in the three cases of partial, total, or no slip between the ground and the tunnel. This mean that the interface effect in this case is negligible. In addition, it is

272 observed a very significant abrupt uplift of the ground under the left tunnel base for the three cases of partial or total or no slip between the ground and the tunnel (Figure 13b). The three curves are almost combined, this mean also that the effect of the interface is very small on the

275 calculation results.

\section{Conclusion:}

277 In this work, the influence of a set of parameters (geometric, geological, etc.) on the behavior 278 of tunnels was examined. The analysis was carried out using the finite element code calculation 279 with an elastoplastic Mohr-coulomb model for the soil, and linear elastic for the support. The 280 analysis of the different curves obtained shows that:

281 - the stresses and deformations induced in the concrete lining of the tunnel and the soil around 282 the tunnel are directly proportional with the depth. The great depth of the tunnel generates 283 strong stresses and strains. These deformations gradually decrease due to the effect of the 284 ground convergence.

285 - the shallow depth of the tunnel causes a remarkable uplift of the soil on the free surface of the 286 soil.

287 - The mid-depth tunnel generates moderate values in terms of stresses, strains, settlement and 288 soil uplift under the tunnel foundation. 
- The circular shape of the cross section of the tunnel generates very low values of settlement, 290 and soil uplift under the base of the tunnel, by comparing with the other two shapes, elliptical 291 and square.

292

293

- The highest stresses and strains induced to the ground are obtained in the case of the interface with full slip compared to the case of the non-slip interface. On the other hand, the case of the zero-slip interface reduces considerably the values of soil settlement, and soil uplift value under the base of the tunnel.

Therefore, it can be concluded that the strongest and most stable tunnel is the mid-deep tunnel with a circular section and with a non-slip interface between the tunnel and the ground. The results of the present study will be useful in the design of such a case by understanding the effects of various influencing parameters which control tunnel stability in poor soil characteristics.

\section{Conflict of interest}

On behalf of all authors, the corresponding author states that there is no conflict of interest.

\section{References}

AFTES, French Association of Works in Underground. (2003a) Characterization of the rock massifs useful for the study and the realization of the underground works, GT1, 88.

AFTES, French Associations of Underground Works. (2003b) Cicatrisation of rock masses useful for the design and construction of underground constructions, tunnel and undergroundworks (no. 177, pp. 2-492). 
Berkane, A. \& Karech, T. (2018) Numerical modeling of the pathological case of a damaged tunnel application to Djebel El-Ouahch tunnel (east-west highway), Asian Journal of Civil Engineering Building and Housing, Volume 19, Number 8.

Berkane A. (2020) Behavior of tunnels during digging in unstable areas ", doctoral thesis, University Batna 2 - Mostefa Ben Boulaïd, Department of Civil Engineering. Batna, Algeria.

Bousbia. N. (2016) Interaction between underground structures, doctoral thesis 2016, University of Skikda, Algeria.

Bultel, F. (2001) Consideration of the swelling of the ground in the sizing of the tunnel's coverings. Engineering sciences [physical]. National School of Roads and Bridges, 2001 French.

Benamar, I. (1996) Study of delayed effects in deep tunnels. Applied geology. National School of Ponts et Chaussées, 1996. French. doctoral thesis.

Grasso, P., Chiriotti, E., \& Xu, S. (2004) Risk control, an essential approach in the development of tunnel studies in difficult terrain. French Review of Geotechnics, 109, 3-21.

Idris, J. (2007). Accidents géotechniques des tunnels et des ouvrages souterrains-Méthodes analytiques pour le retour d'expérience et la modélisation numérique (Doctoral dissertation, Institut National Polytechnique de Lorraine).

Khoshnoudian, F. (1999) Study of the behavior of tunnels under seismic loading” Doctoral theses, Lille Mechanical Laboratory, Soils-Structures Department.

Mezhoud, S., Clastres, P., Houari, H., \& Belachia, M. (2017) Forensic investigation of causes of premature longitudinal cracking in a newly constructed highway with a composite pavement system. Journal of Performance of Constructed Facilities, 31(2), 04016095. 
334 Mezhoud, S., Clastres, P., Houari, H., \& Belachia, M. (2018) Field Investigations on Injection

335 Method for Sealing Longitudinal Reflective Cracks. Journal of Performance of Constructed $336 \quad$ Facilities, 32(4), 04018041.

338 Oggeri, C., \& Ova, G. (2004) Quality in tunnelling: ITA-AITES working group 16 final reports. 339 Tunnelling and Underground Space Technology, 4, 239-272.

340 Owen, G., Scholl, R. (1981) Earthquke engineering of large underground structures. Federal Highway Administration and national Science Foundation.

342 Panet \& Guellec. (1974): Contribution to the study of retaining a tunnel at the back of the face.1974. In Proc. 3th Int. Cong. Rock Mech., Denver, Vol. IIB.

344 Panet, M. (1995). Le calcul des tunnels par la méthode convergence-confinement. Presses ENPC.

Patil, M., Choudhury, D., Ranjith, P., Zhao, J. (2018). Behavior of shallow tunnel in soft soil under seismic conditions. Journal of Tunnelling and Underground Space Technology, 82, $30-38$.

Peila, D. (1994) A theoritical study of reinforcement influence on the stability of tunnel face. Geotechnical and geological engineering, 12(3), pp 145-168.

Sliteen, I. (2013) Three-dimensional modeling of the seismic behavior of tunnels in soft ground" Doctoral thesis, Civil Engineering and Geo-Environment Laboratory, Doctoral School of Engineering Sciences, University of Lille1 Sciences and Technologies

Tsinidis, G., Pitilakis, K., Heron, C., \& Madabhushi, G. (2013). Experimental and numerical investigation of the seismic behavior of rectangular tunnels in soft soils. COMPDYN conference, Greece, 12-14 June 2013. 
Figures
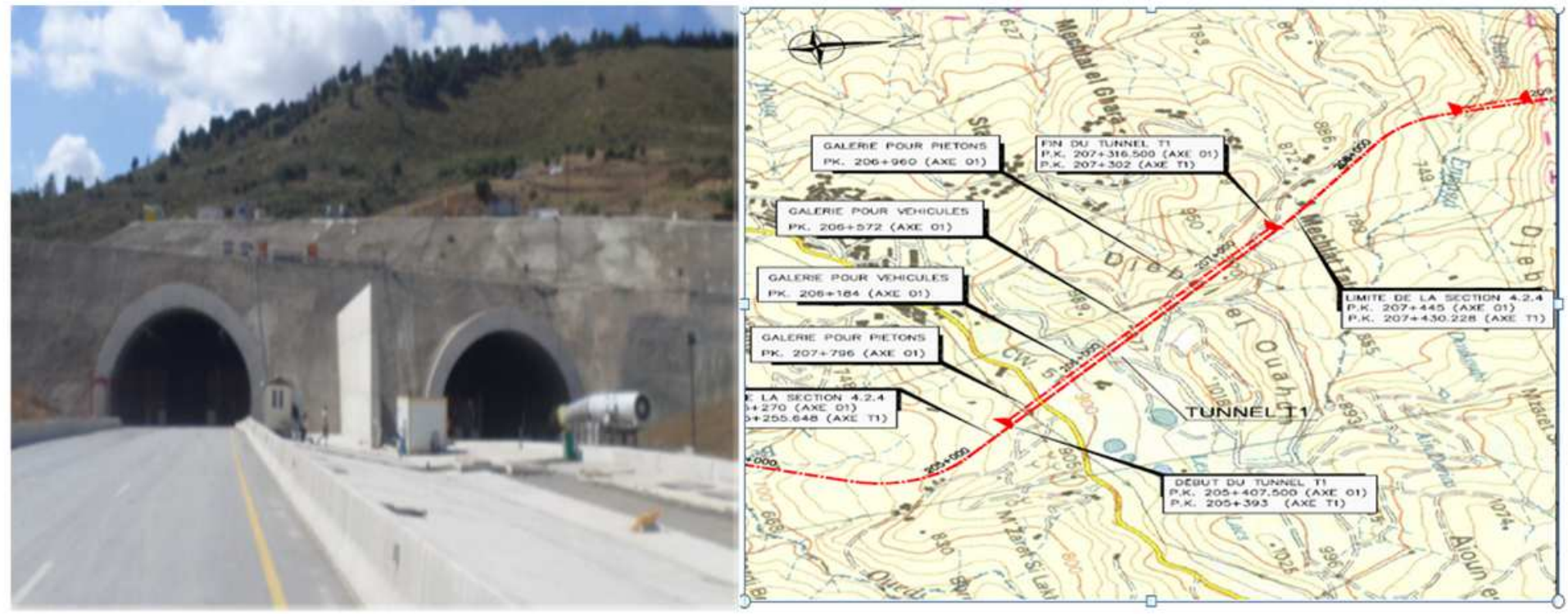

Figure 1

a) General view of two tubes of tunnel. b) Plan layout of the tunnel Note: The designations employed and the presentation of the material on this map do not imply the expression of any opinion whatsoever on the part of Research Square concerning the legal status of any country, territory, city or area or of its authorities, or concerning the delimitation of its frontiers or boundaries. This map has been provided by the authors.

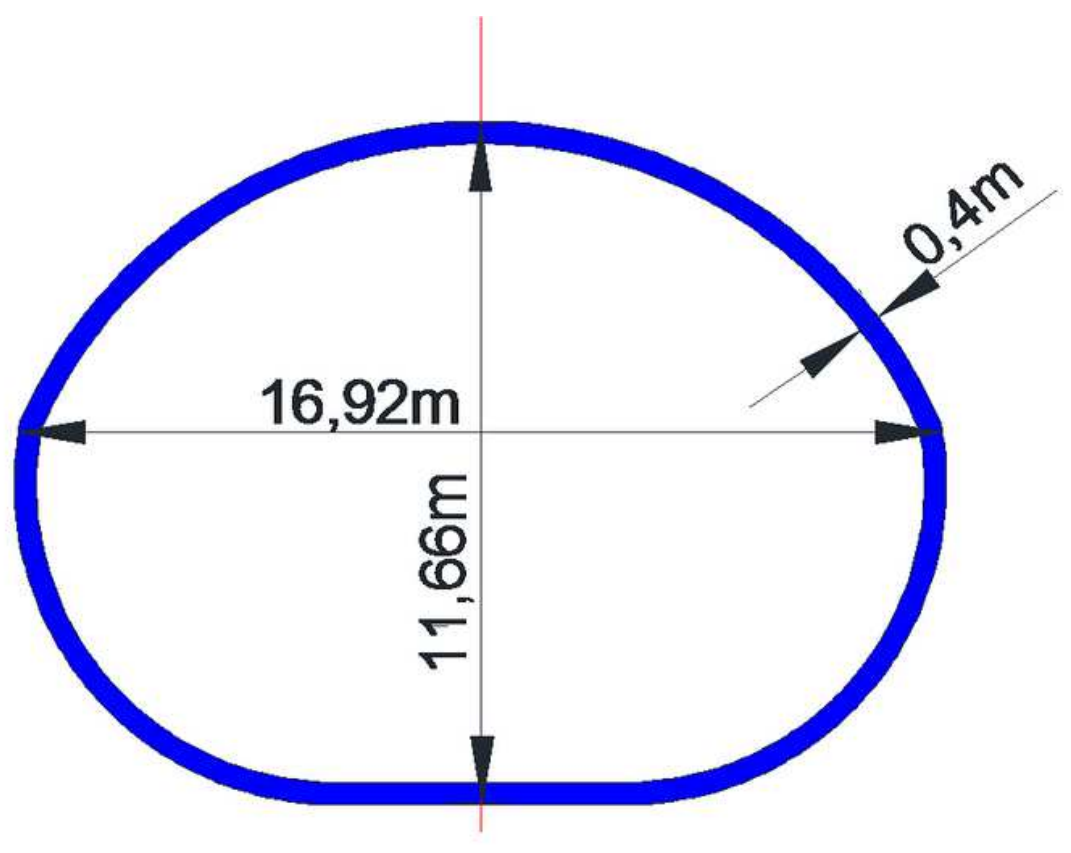

Figure 2

Transverse dimensions of the tunnel 


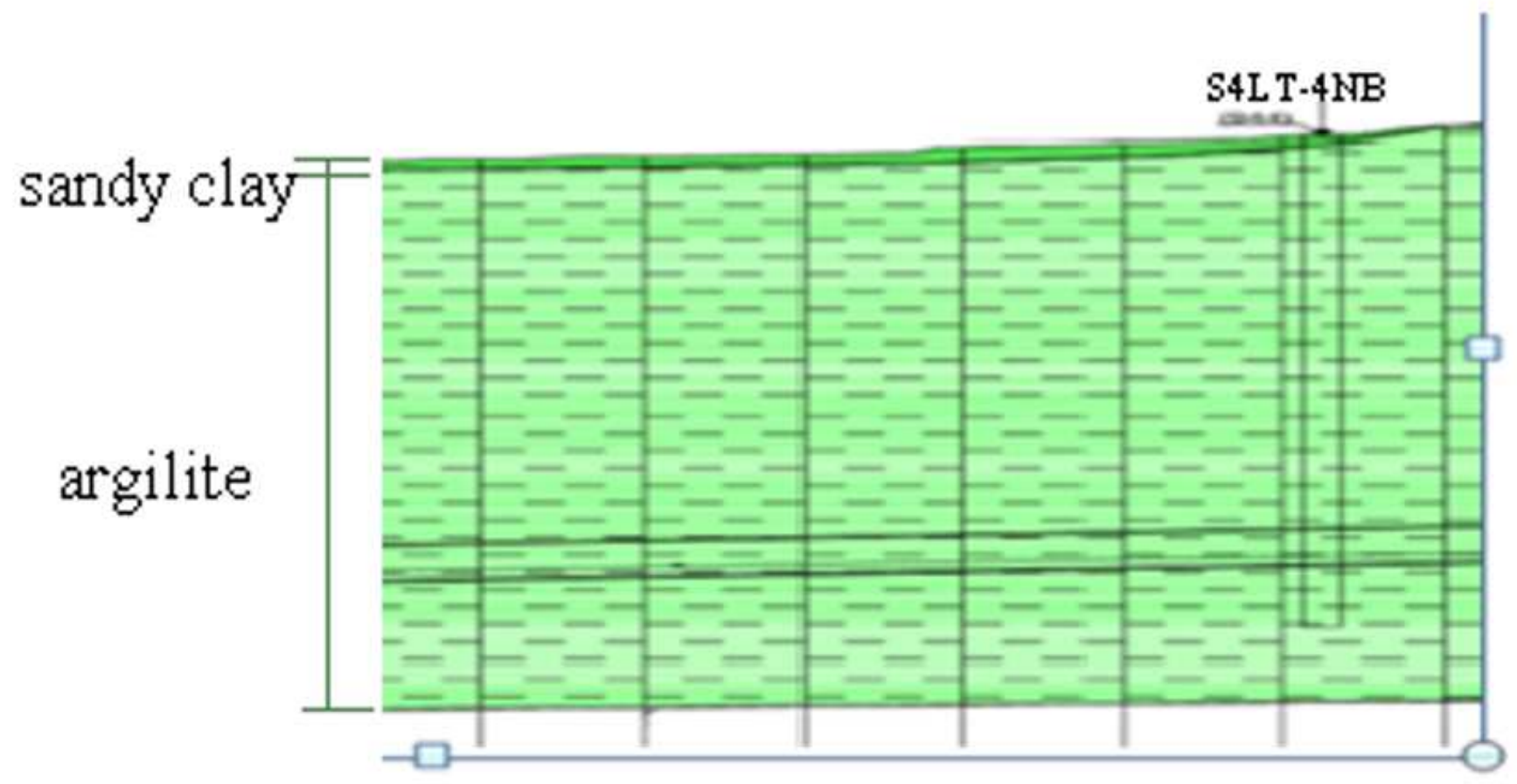

Figure 3

Geological section of the terrain (according to the project documents). 


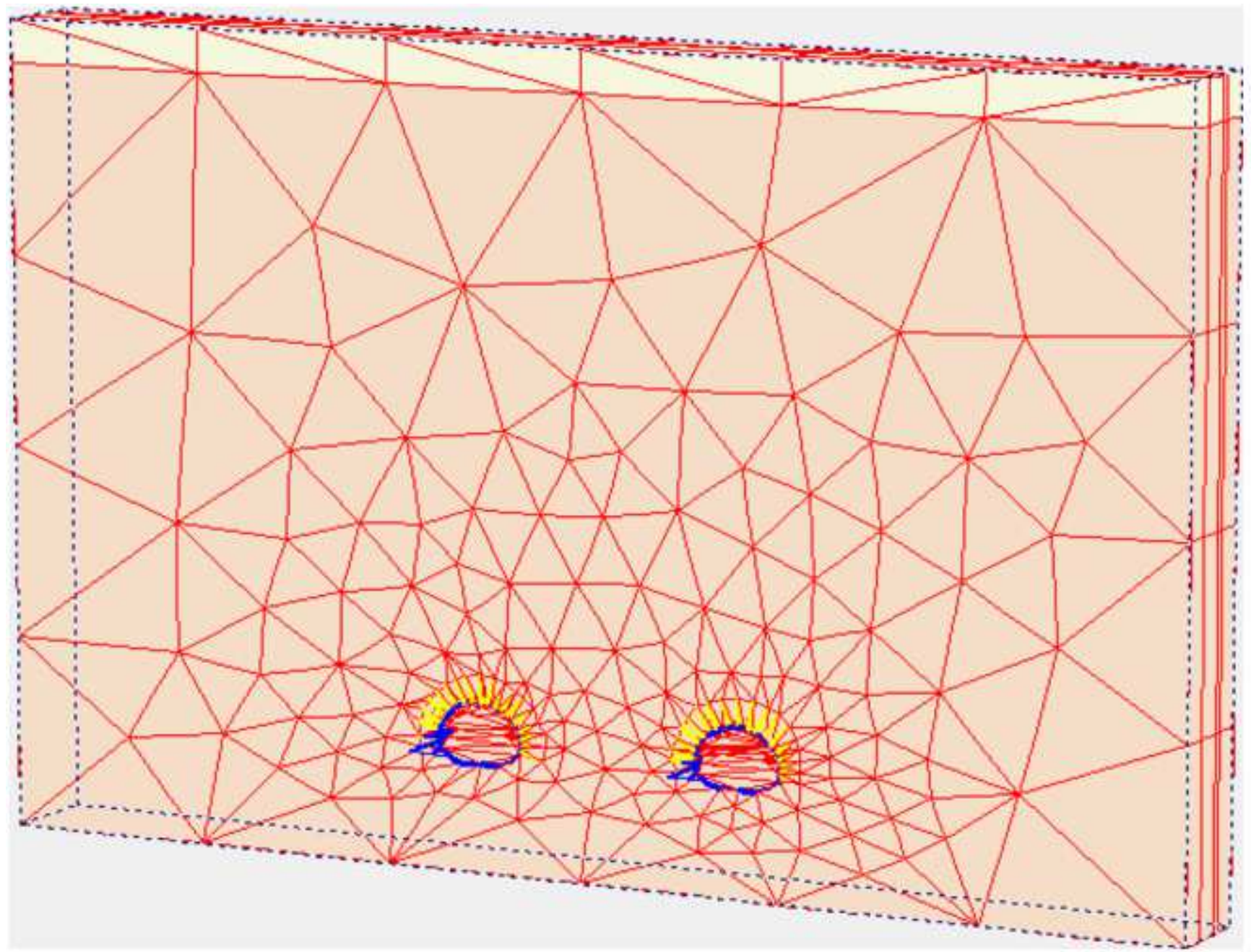

Figure 4

The geometry and the mesh of model in 3D

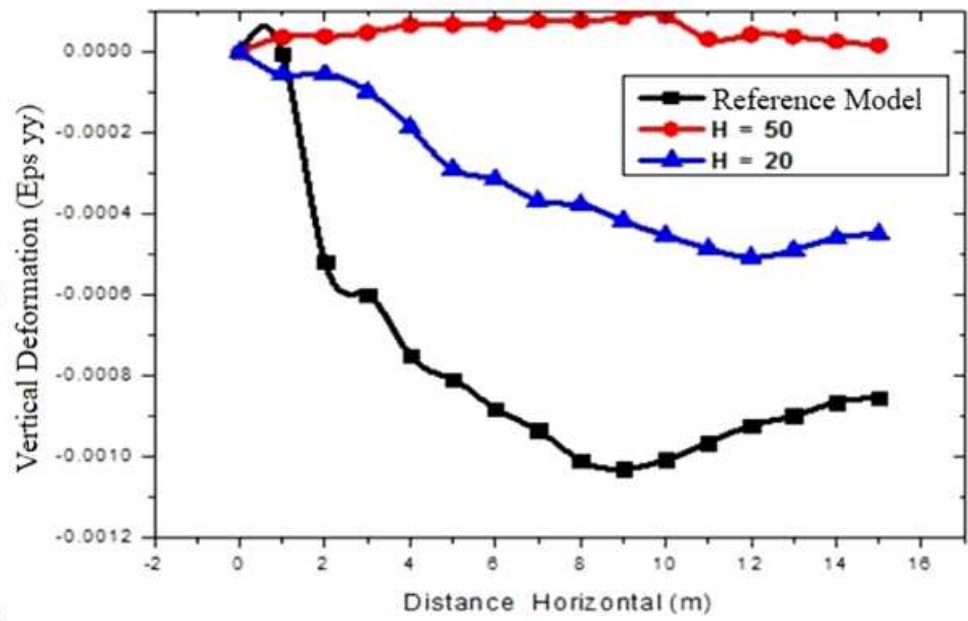

Figure 5

The state of the Stresses (a) and deformation (b) induced in the soil around the wall of the left tube 

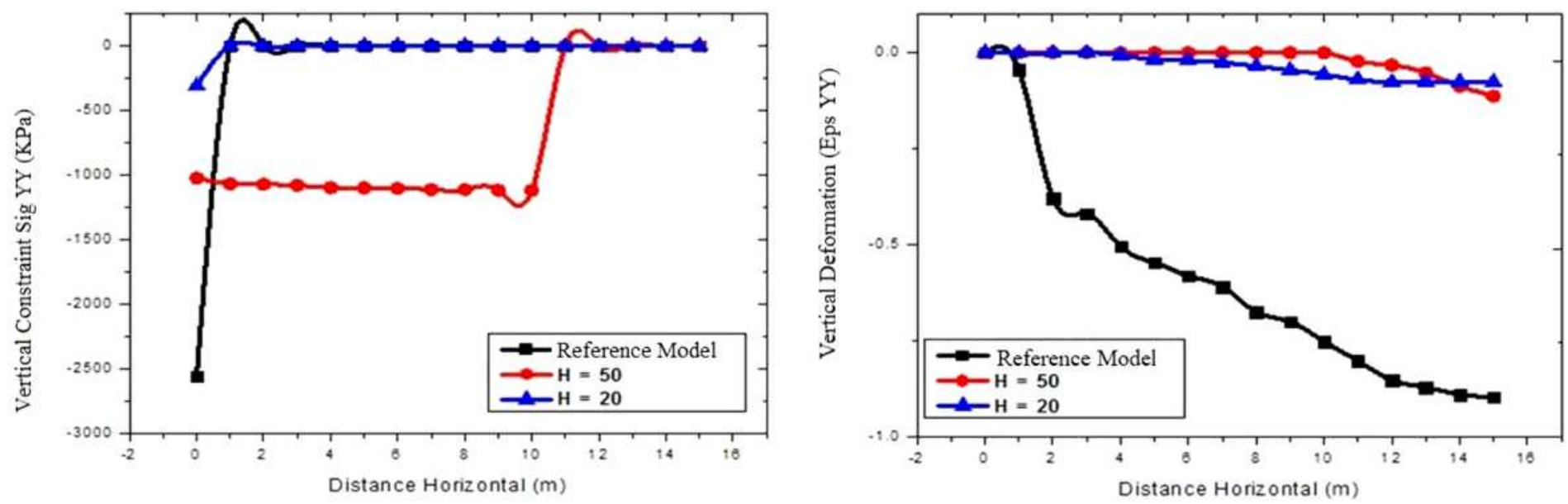

Figure 6

The state of the stresses (a) and the state of Deformations (b) induced in the wall of the left tube.
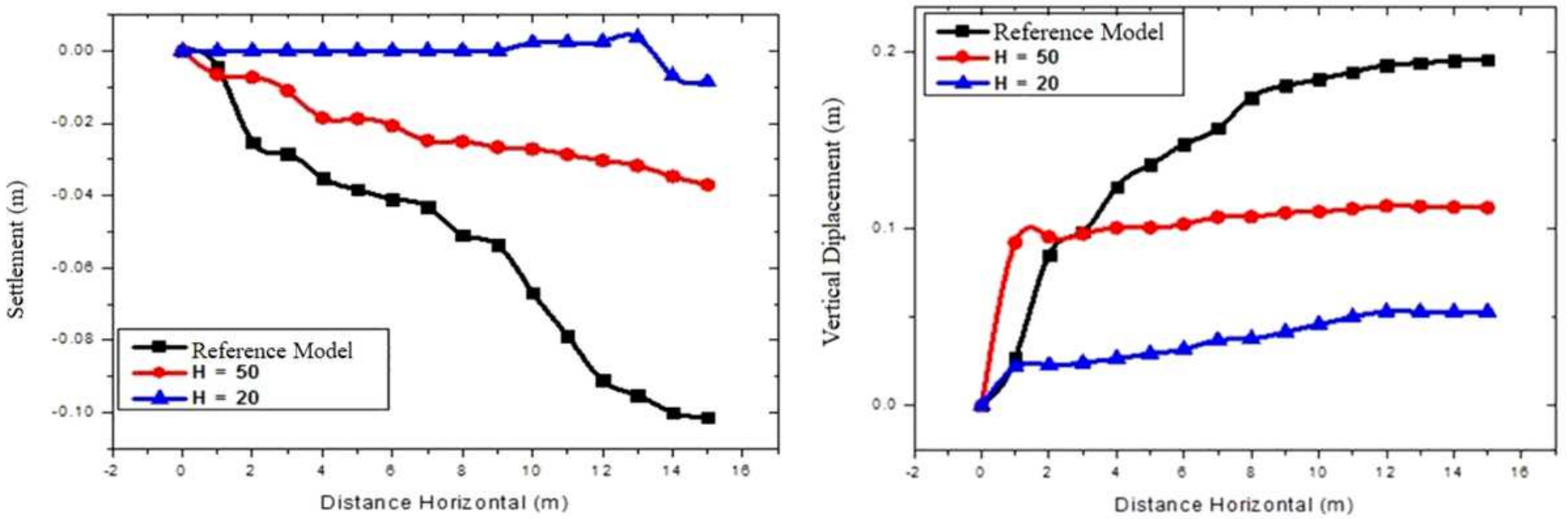

Figure 7

Settlement at the ground surface above the left tube (a); and vertical displacement under the left tube raft (b)
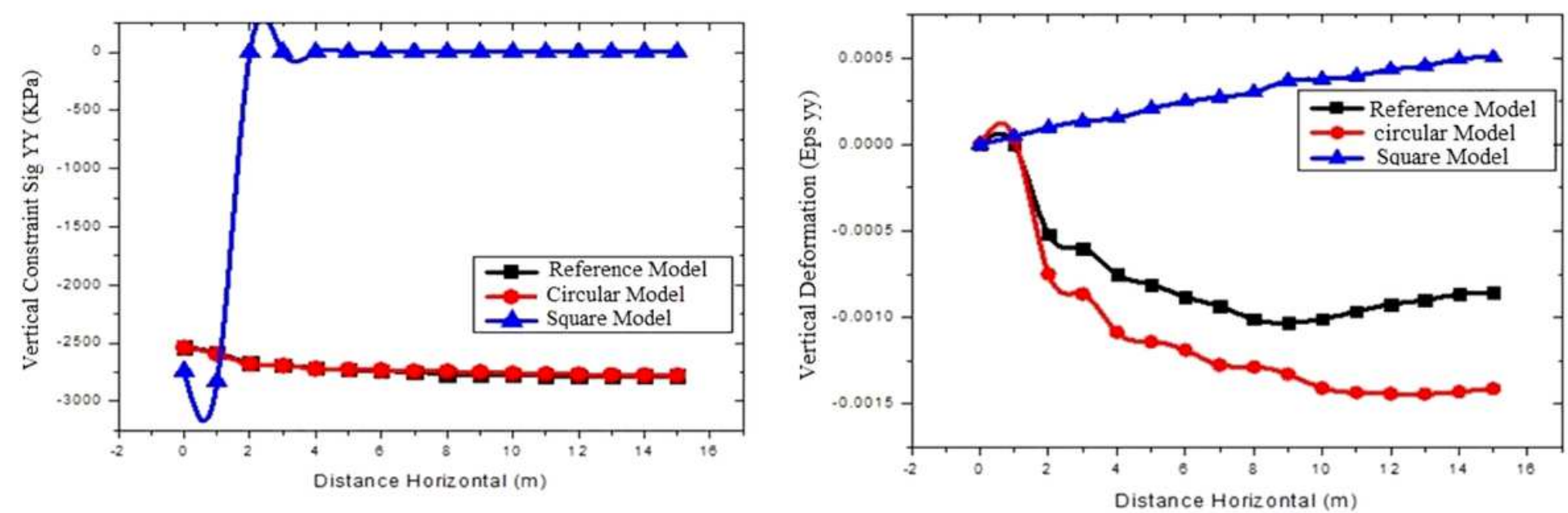
Figure 8

The state of the Stresses (a) and deformation (b) induced in the soil around the wall of the left tube
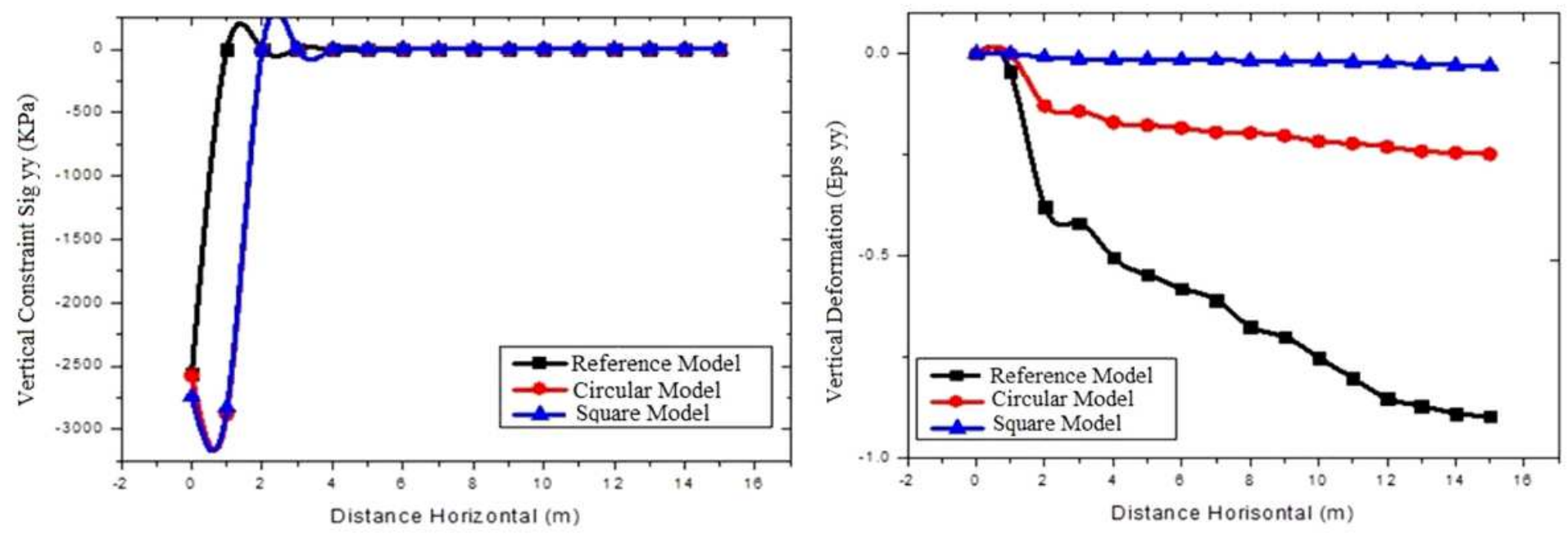

Figure 9

The state of the stresses (a) and the state of Deformations (b) induced in the wall of the left tube.
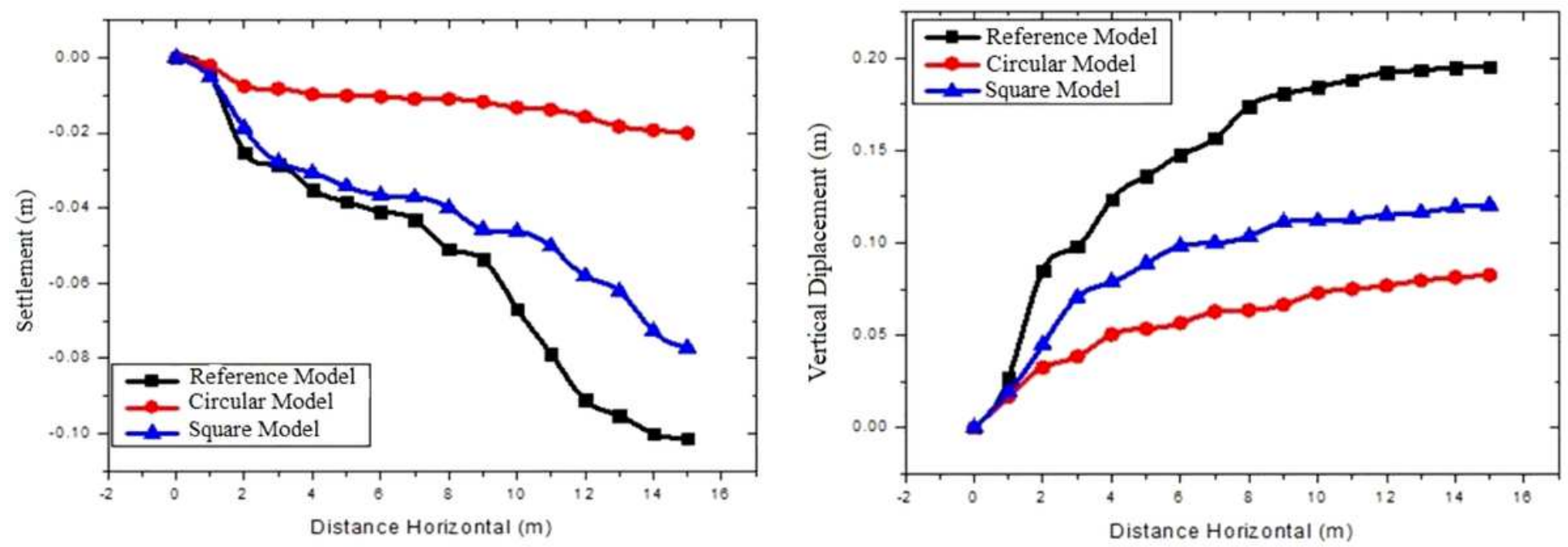

Figure 10

Settlement at the ground surface above the left tube (a); and vertical displacement under the left tube raft (b) 

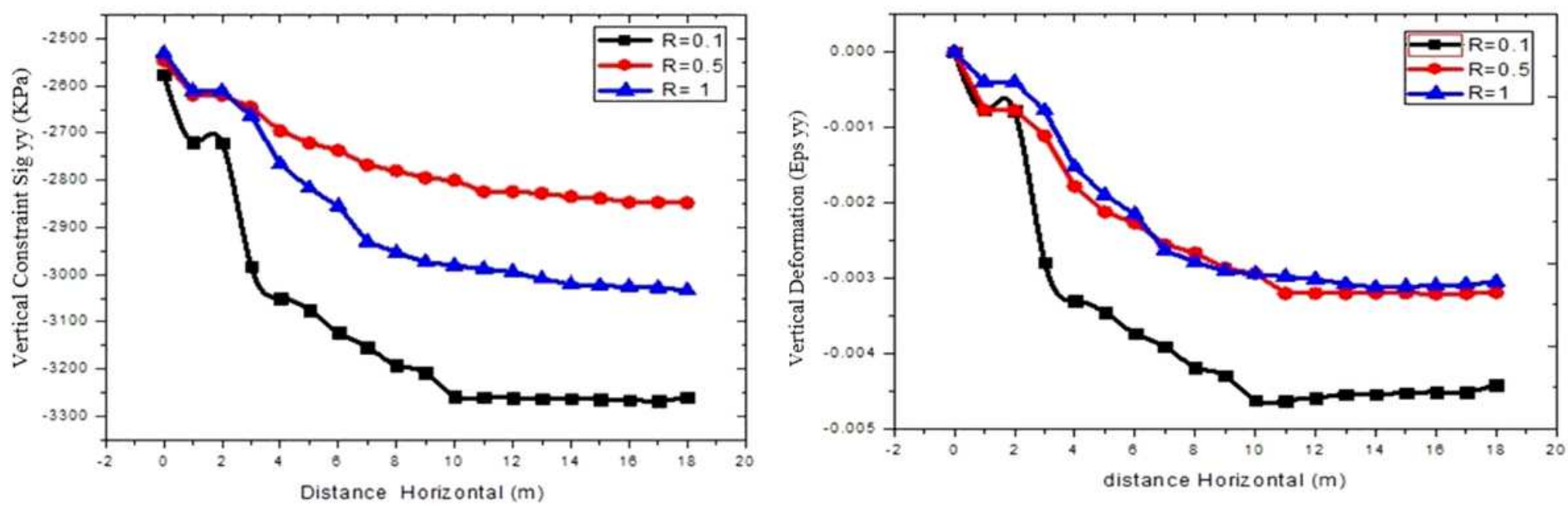

Figure 11

The state of the Stresses (a) and deformation (b) induced in the soil around the wall of the left tube
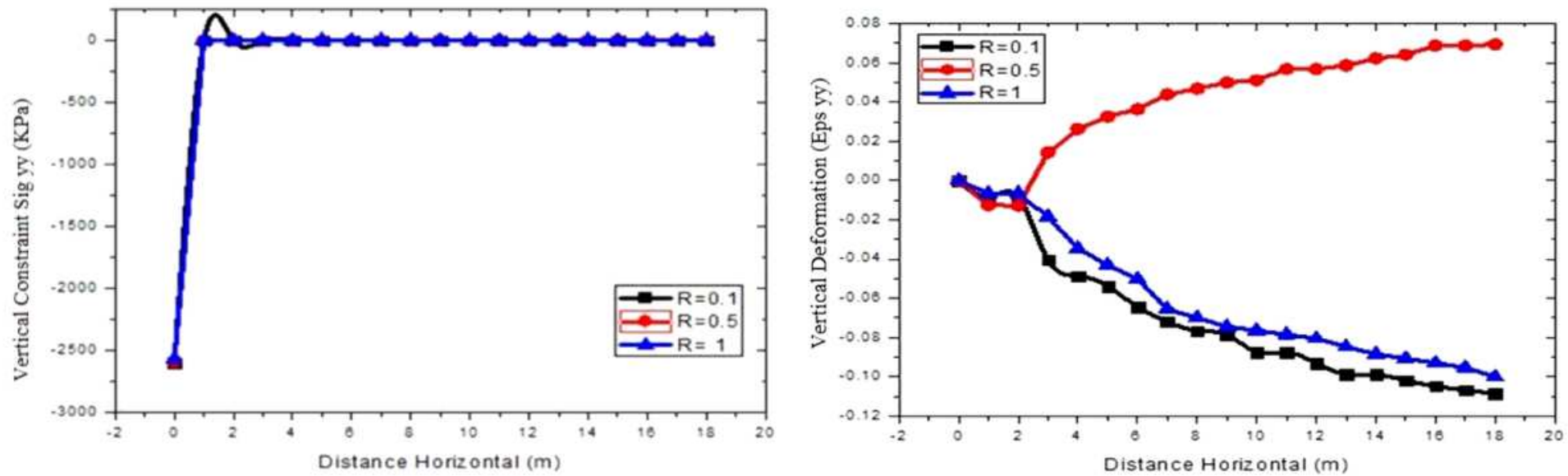

Figure 12

The state of the stresses (a) and the state of Deformations (b) induced in the wall of the left tube.
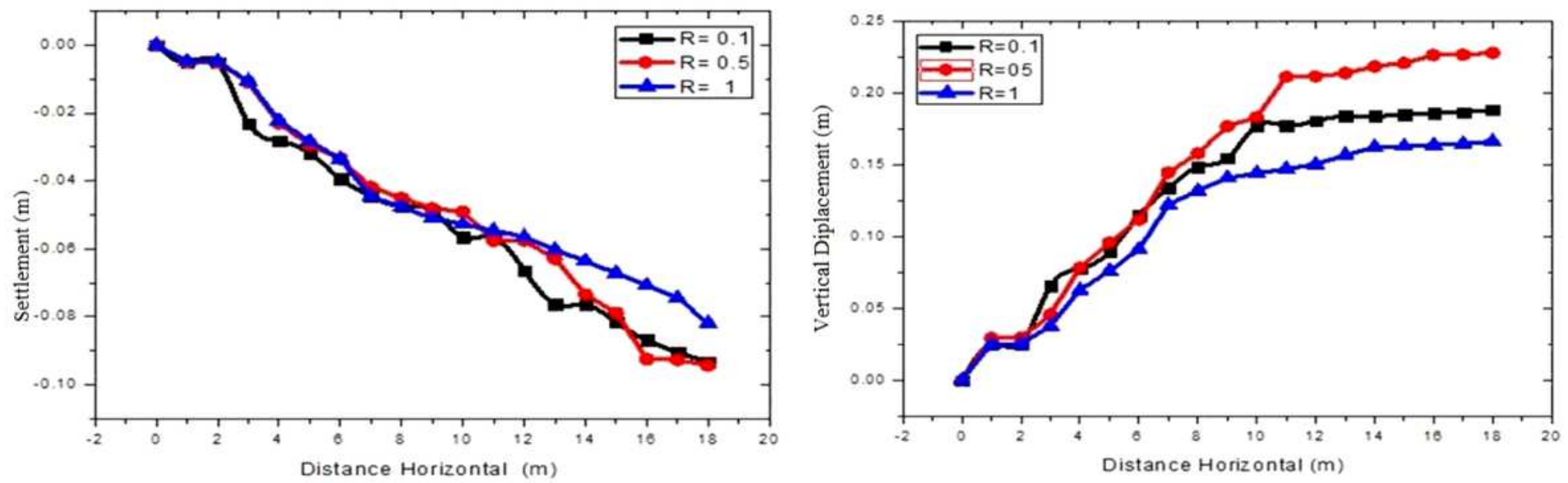

Figure 13 
Settlement at the ground surface above the left tube (a); and vertical displacement under the left tube raft (b) 